\title{
Comparison between ISO 5008 and field whole body vibration tractor values
}

\author{
Roberto Deboli, ${ }^{1}$ Angela Calvo, ${ }^{2}$ Christian Preti' \\ 'Italian Research Council, Institute for Agricultural and Earthmoving Machinery, Torino, Italy \\ ${ }^{2}$ Department of Agricultural, Forestry and Environmental Economics and Engineering, University \\ of Torino, Italy
}

\begin{abstract}
The exposure to whole body vibration (WBV) of tractor drivers during field operations is a problem that has never been solved. WBV values are quite difficult to predict because of the high number of variables, such as mass and geometry of the vehicle, forward speed, tire pressure, type of ground, operation cycle, and environmental factors. The use of an artificial track is useful to limit the variability of some field parameters, such as the path followed, fluctuations in speed, weather, temperature, and soil conditions. For comparative purposes, these variables need to be maintained as constant as possible in order to obtain the most useful data.

An analysis of the literature provoked the question: Is there a lower forward speed on artificial track that can generate the same vibration response on tractors working in the same field?

In this paper, we analyze the available literature and provide some WBV values and frequency analysis of acceleration measured on agricultural tractors traveling on an artificial test track and on different types of ground.
\end{abstract}

Correspondence: Roberto Deboli, Italian Research Council, Institute for Agricultural and Earthmoving Machinery, Strada delle Cacce 73,

10135, Torino, Italy. Tel. +39.011.3977710 - Fax: +39.011 .3489218 .

E-mail: r.deboli@imamoter.cnr.it

Key words: whole body vibration, artificial test track, agricultural tractors.

Acknowledgements: the authors wish to thank Giuseppe Paletto, IMAMOTER Institute, for the field work.

This study is part of a PRIN project (2009), Analysis of the rollover and the vibration in the agricultural tractors with respect to current safety legislation, funded by the Italian Ministry of Education, University and Research (MIUR).

Received for publication: 9 December 2011.

Accepted for publication: 17 April 2012.

(C) Copyright R. Deboli et al., 2012

Licensee PAGEPress, Italy

Journal of Agricultural Engineering 2012; XLIII:e8

doi:10.4081/jae.2012.e8

This article is distributed under the terms of the Creative Commons Attribution Noncommercial License (by-nc 3.0) which permits any noncommercial use, distribution, and reproduction in any medium, provided the original author(s) and source are credited.

\section{Introduction}

Tractor drivers are exposed to high levels of whole body vibration (WBV) during field operations and on/off road transportation (Bovenzi, 1994). The consequences of low-frequency vibration produced by agricultural vehicles can be extremely severe and depend on different variables, such as soil type, field operations, tractor mass distribution and forward speed (Lines, 1995; Scarlett, 2007; Maytona, 2008). Studies have been carried out to analyze vibration transmitted to the driver's seat, both in controlled and standardized conditions (Banfo, 1997; Deprez, 2005a; Deprez, 2005b; Paddan, 2002; Scarlett, 2007). Many of these studies have been carried out according to the international standard ISO 2631-1 (1997). This standard provides a simple definition of the whole body vibration measurement by defining a methodology to calculate the vibration exposure. It does not, however, judge the values obtained or establish any limits. It only provides a methodology to measure and calculate vibration in general situations, but does not give indications as to how to measure machine vibration in the workplace.

The more recent EN 1032 (2003) and CEN ISO/TR 25398 (2006) standards have attempted to deal with this problem, although no simple solutions are provided. For example, these standards do not describe surface characteristics and use statistical analysis to obtain vibration values at the driving seat.

Furthermore, WBV data analysis in the agricultural sector is even more complex than in industry because it is strictly connected to the surface type and conditions, as well as to machine configuration and the type of operation being undertaken. These variables mean that it may be difficult to compare vibration data collected during the same agricultural task being carried out under different conditions (Deboli, 2008).

More homogeneous data may be obtained using normalized tracks. The ISO 5008 standard (2001) has been set up to measure driver vibration on normalized tracks: smooth (100 m long) and rough $(35 \mathrm{~m}$ long). This standard specifies methods to measure and report WBV at the driving seat on an agricultural wheeled tractor running on an artificial test track at specified forward speeds. The use of an artificial track is useful because it limits the variability of some field parameters, such as the path followed, fluctuations in speed, weather, temperature, and soil conditions.

For comparative purposes, these variables need to be maintained as constant as possible in order to obtain the most useful data. ISO 5008 (2001), in-field and on-farm tests have been carried out to study WBV on agricultural vehicles at the Silsoe Research Institute (Scarlett, 2005). The purpose of this research was to use an artificial track to simulate field and farm tractor operations. Tractor forward speeds on the IS0-smooth track were those standardized: 10, 12, 13, 14, 15, 16, $18,20,24,30 \mathrm{~km} / \mathrm{h}$. The authors found WBV emission levels increased 
in proportion to forward speed, irrespective of the type of suspension systems on the test vehicles. Field operations were then carried out (ploughing, plough transport, cultivating, spraying and trailer transport) and corresponding WBV were measured. There was little similarity between ISO WBV track and field data because of the high acceleration values measured on tractors running on the ISO track at the above-mentioned standardized speeds.

Our analysis of the Silsoe results provoked the question: Is there a lower forward speed on artificial track that can generate the same vibration response on tractors working in the field? The aim of this paper was to find an answer. For this reason, in order to analyze and compare WBV values three new unballasted tractors, not coupled to machinery, as requested by ISO 5008 (2001), were run on both an ISO-smooth track and on different surfaces, while carrying out typical agricultural operations.

\section{Materials and methods}

\section{Tractors}

We tested three brand new tractors straight from the factory. These models are commonly used in different agricultural situations (Table 1): category A (EEC, 1978) class I (unladen mass $<3600 \mathrm{~kg}$ ) and class II $(3600 \mathrm{~kg}<$ unladen mass $<6500 \mathrm{~kg})$. None of the tractors had a cab or axle suspension systems. For this reason, ground unevenness was only filtered by the tires. Tractor A was a two-wheel drive vehicle equipped with radial tires while tractors $B$ and $C$ were four-wheel drive equipped with low profile tires. All vehicles were fitted with parallelogram-type suspension seats with mechanical spring and damper suspension systems.

Tractors were equipped as originally furnished by manufacturers and ballasts or implements were not added (as required by ISO 5008 standard). The User's Manual was consulted for tire pressure.

\section{Track description}

All tractors were run over typical agricultural surfaces (grass, harrowed clay, unmetalled farm roadway, asphalt road) and on an ISOsmooth track. Tests were conducted at the CNR IMAMOTER testing facilities (Pratofiorito, Turin, Italy). For the artificial track tests, vibration was measured when the tractor was driven over a $100 \mathrm{~m}$ ISOsmooth track. This track consisted of two parallel strips suitably spaced for the wheel track of the tractor. The surface of each strip was formed of wooden slats $80 \mathrm{~mm}$ wide, each slat separated from the next by a gap of $80 \mathrm{~mm}$. Slats were sited firmly in a base frame. The surface of each strip of track was defined by the cordinates of elevation with respect to a level base, as listed in the ISO 5008 tables.

The other test tracks (grass, harrowed clay, asphalt and unmetalled farm road) were located at the IMAMOTER experimental field site. Track surfaces were: grass (1400 m long), flat and homogeneous harrowed clay (1200 m long), smooth asphalt (1000 m long), uneven ground with random subsidence of different heights (max. 2-3 cm), unmetalled farm road (2000 $\mathrm{m}$ long).

\section{Forward speed}

On these surfaces, tractors were run at forward speeds typical of some agricultural operations (e.g. haymaking and chemical fertilizing) and of some off-road transfers, as described in Table 2. For tests over asphalt, machines were driven at their highest forward speed. In order to obtain steady results over these surfaces, data were collected over quite a long period of time ( $\geq 5 \mathrm{~min}$ ).

Tractors were then run on the ISO-smooth track (ISO, 2001) at speeds from 1 to $14 \mathrm{~km} / \mathrm{h}$, with regular increases of $0.5 \mathrm{~km} / \mathrm{h}$. Forward speed was monitored by radar (using a Doppler radar sensor). For tests on ISO-smooth track, acquisition times were related to the machine forward speed ( $350 \mathrm{~s}$ for $1 \mathrm{~km} / \mathrm{h}, 24 \mathrm{~s}$ for $14 \mathrm{~km} / \mathrm{h}$ ). At least three repetitions were run for each velocity.

\section{Whole body vibration measures measures}

Acceleration levels were measured on the cab floor of the three tested agricultural tractors. In this first phase, only data measured over the platform have been considered because previous tests had shown that vibration values measured on the seat changed. In fact, in these cases, it was pointed out that seats in some situations showed the resonance phenomenon. This is, however, beyond the scope of the present work and requires more in-depth study.

A total of 360 tests were carried out. To improve the accuracy of RMS value analysis, for each test, we recorded and analyzed acceleration values of both root mean square (RMS) values along the $\mathrm{x}$ (longitudinal), $\mathrm{y}$ (transverse) and $\mathrm{z}$ (vertical) axes, and the $1 / 3$ octave band spectrum. The same operator (mass $70 \mathrm{~kg}$, height $180 \mathrm{~cm}$ ) drove in the same way for all tests.

\section{Instrument}

For data acquisition, we used a measuring chain formed by one triaxial accelerometer (Bruel \& Kjaer, 4322), three charge amplifiers (Bruel \& Kjaer, 2635) and a digital audio tape recorder (Teac, RD-120 TE). The triaxial accelerometer was fixed on the cab floor under driving seat. A dual channel real-time frequency analyzer (Bruel \& Kjaer, 2133) was used for data frequency analysis in the $0.5-80 \mathrm{~Hz}$ band; this range is interesting from a hygienist's point of view for WBV exposure, as reported in the ISO 2631-1 (ISO, 1997). The two whole body weighting filters, Wd for x (longitudinal) and y (transversal) axes, Wk for z (vertical) axis, were applied as requested by ISO 2631-1 (1997). A photocell driven acoustic device was used during tests over the ISO track. This acoustic signal was recorded on a digital recorder to signal the beginning and the end of data collection.

\section{Standards}

The International Standard ISO 5008 was used (ISO, 2001). This standard defines the specification of instruments, measurement proce-

Table 1. Tractor characteristics as presented in the User's Manual.

\begin{tabular}{|c|c|c|c|c|c|c|}
\hline Tractor & Class & Traction & $\begin{array}{c}\text { Mass } \\
\text { (kg) }\end{array}$ & Front 1 & $\begin{array}{l}\text { Tires } \\
\text { Pressure Rear P } \\
(105 \mathrm{~Pa})\end{array}$ & $\begin{array}{c}\text { Pressure } \\
\left(10^{5} \mathrm{~Pa}\right)\end{array}$ \\
\hline A & I & $2 W D$ & 3430 & $10.00-16$ & $2.03 \quad 18.4-34$ & 1.62 \\
\hline B & II & 4WD & 4080 & $480 / 65$ R24 & $4 \quad 1.22 \quad 600 / 65$ R34 & $34 \quad 1.22$ \\
\hline $\mathrm{C}$ & II & 4WD & 4390 & 480/65 R24 & $4 \quad 1.62 \quad 540 / 65$ R38 & $38 \quad 1.62$ \\
\hline
\end{tabular}

Table 2. Tractor forward speed on different test surfaces.

\begin{tabular}{lcc} 
Tractor & Test surfaces & $\begin{array}{c}\text { Forward speed, } \\
\mathbf{k m} / \mathbf{h}\end{array}$ \\
$\mathrm{A}, \mathrm{B}, \mathrm{C}$ & Grass track & 10 \\
$\mathrm{~A}, \mathrm{~B}, \mathrm{C}$ & Harrowed clay & 10 \\
\hline $\mathrm{A}, \mathrm{B}$ & Asphalt & 30 \\
C & Asphalt & 41 \\
\hline A & Farm roadway & 10 \\
B, C & Farm roadway & 14 \\
\hline
\end{tabular}


dures, measurement site characteristics and frequency weighting to be used for acceptably precise data collection when measuring and recording WBV on agricultural wheeled tractors. Vibration values were evaluated in accordance with the current standard (ISO 2631-1, 1997). This includes means of weighting the vibration levels at different frequencies in order to take into consideration the frequency sensitivity of the driver's body to WBV.

\section{Results}

Global acceleration values were analyzed for each tractor, surface and direction ( $\mathrm{x}, \mathrm{y}$ and $\mathrm{z}$ axes), as well as acceleration frequency distribution (1/3 octave band). It was observed that ISO 5008-smooth track may sometimes reproduce, at specified speeds, the same vibratory conditions registered over other surfaces in terms of RMS acceleration values and spectral trend.

Two case studies have been considered.

\section{Global acceleration values}

Acceleration data analysis was performed separately along the three axes to underline the acceleration behavior along the three directions as a function of the surface type.

Tables 3,4 and 5 show tractor acceleration source values measured for the $\mathrm{x}, \mathrm{y}$ and $\mathrm{z}$ axes during all tests. Horizontal ( $\mathrm{x}$ and $\mathrm{y}$ axes) components were not multiplied by the 1.4 factor. Each tractor traveled on ISO track, grass, harrowed clay, asphalt and unmetalled tracks at the speed reported in the three tables. The speed that generated the weighted RMS accelerations on the ISO-smooth track more closely similar to the weighted RMS values recorded on the other tracks examined was considered. In the case of horizontal components ( $\mathrm{x}$ and $\mathrm{y}$ axes), the RMS values over the ISO-smooth track were higher than those registered over the other surfaces. Differences in RMS were remarkably high in the direction of $\mathrm{x}$, reaching values of around $100 \%$ in tests on asphalt and the unmetalled farm roadway (Table 3, column 7). These last tracks were not able to create horizontal fluctuation over the tractor cab floor. Also, the fact that the tractor was not towing an agricultural

Table 3. X axis, acceleration root mean square values measured on the tractor cab floor (all tracks) at the speeds which generated similar root mean square data and their absolute variation rate.

\begin{tabular}{|c|c|c|c|c|c|c|}
\hline Tractor & $\begin{array}{l}\text { Test } \\
\text { surfaces }\end{array}$ & $\begin{array}{c}\text { Forward speed, } \\
\text { km/h }\end{array}$ & $\begin{array}{l}\text { RMS value, } \\
\mathrm{m} / \mathrm{s}^{2}\end{array}$ & $\begin{array}{l}\text { Forward speed on } \\
\text { ISO track, km/h }\end{array}$ & $\begin{array}{l}\text { RMS value on ISO track, } \\
\mathrm{m} / \mathrm{s}^{2}\end{array}$ & $\begin{array}{c}\text { Absolute acceleration } \\
\text { variation rate, } \%\end{array}$ \\
\hline A & Grass track & 10 & 0.20 & 4.0 & 0.27 & 35 \\
\hline B & Grass track & 10 & 0.16 & 4.5 & 0.23 & 44 \\
\hline $\mathrm{C}$ & Grass track & 10 & 0.22 & 4.5 & 0.24 & 9 \\
\hline A & Harrowed clay & 10 & 0.31 & 6.0 & 0.32 & 3 \\
\hline B & Harrowed clay & 10 & 0.20 & 4.5 & 0.23 & 15 \\
\hline $\mathrm{C}$ & Harrowed clay & 10 & 0.25 & 4.5 & 0.24 & 4 \\
\hline A & Asphalt & 30 & 0.23 & 6.0 & 0.32 & 39 \\
\hline B & Asphalt & 30 & 0.11 & 4.5 & 0.23 & 109 \\
\hline $\mathrm{C}$ & Asphalt & 41 & 0.20 & 4.5 & 0.24 & 20 \\
\hline A & Farm roadway & 10 & 0.13 & 5.0 & 0.27 & 108 \\
\hline B & Farm roadway & 14 & 0.12 & 4.5 & 0.23 & 92 \\
\hline $\mathrm{C}$ & Farm roadway & 14 & 0.16 & 4.5 & 0.28 & 75 \\
\hline
\end{tabular}

RMS, root mean square.

Table 4. Y axis, root mean square values measured on the tractor cab floor for all tracks at the speeds that generated similar root mean square data and their absolute variation rate.

\begin{tabular}{|c|c|c|c|c|c|c|}
\hline Tractor & $\begin{array}{l}\text { Test } \\
\text { surfaces }\end{array}$ & $\begin{array}{c}\text { Forward speed, } \\
\mathrm{km} / \mathrm{h}\end{array}$ & $\begin{array}{l}\text { RMS value, } \\
\mathrm{m} / \mathrm{s}^{2}\end{array}$ & $\begin{array}{l}\text { Forward speed on } \\
\text { ISO track, } \mathrm{km} / \mathrm{h}\end{array}$ & $\begin{array}{l}\text { RMS value on ISO track, } \\
\mathrm{m} / \mathrm{s}^{2}\end{array}$ & $\begin{array}{l}\text { Absolute acceleration } \\
\text { variation rate, } \%\end{array}$ \\
\hline A & Grass track & 10 & 0.36 & 2 & 0.26 & 28 \\
\hline B & Grass track & 10 & 0.29 & 2 & 0.26 & 10 \\
\hline $\mathrm{C}$ & Grass track & 10 & 0.32 & 3 & 0.37 & 16 \\
\hline A & Harrowed clay & 10 & 0.42 & 3 & 0.50 & 19 \\
\hline B & Harrowed clay & 10 & 0.30 & 2 & 0.26 & 13 \\
\hline $\mathrm{C}$ & Harrowed clay & 10 & 0.30 & 3 & 0.37 & 23 \\
\hline A & Asphalt & 30 & 0.13 & 1 & 0.15 & 15 \\
\hline B & Asphalt & 30 & 0.10 & 1 & 0.16 & 60 \\
\hline $\mathrm{C}$ & Asphalt & 41 & 0.13 & 2 & 0.37 & 185 \\
\hline A & Farm roadway & 10 & 0.32 & 2 & 0.26 & 19 \\
\hline B & Farm roadway & 14 & 0.25 & 2 & 0.26 & 4 \\
\hline $\mathrm{C}$ & Farm roadway & 14 & 0.28 & 3 & 0.37 & 32 \\
\hline
\end{tabular}

RMS, root mean square. 
Table 5. $\mathrm{Z}$ axis, root mean square values measured on the tractor cab floor for all tracks at the speeds that generated similar root mean square data and their absolute variation rate.

\begin{tabular}{|c|c|c|c|c|c|c|}
\hline Tractor & $\begin{array}{l}\text { Test } \\
\text { surfaces }\end{array}$ & $\begin{array}{l}\text { Forward speed, } \\
\text { km/h }\end{array}$ & $\begin{array}{l}\text { RMS value, } \\
\mathrm{m} / \mathrm{s}^{2}\end{array}$ & $\begin{array}{l}\text { Forward speed on } \\
\text { ISO track, km/h }\end{array}$ & $\begin{array}{l}\text { RMS value on ISO track, } \\
\mathrm{m} / \mathrm{s}^{2}\end{array}$ & $\begin{array}{l}\text { Absolute acceleration } \\
\text { variation rate, } \%\end{array}$ \\
\hline A & Grass track & 10 & 0.75 & 4.5 & 0.71 & 5 \\
\hline B & Grass track & 10 & 0.58 & 4.5 & 0.55 & 5 \\
\hline $\mathrm{C}$ & Grass track & 10 & 0.69 & 4.5 & 0.62 & 10 \\
\hline A & Harrowed clay & 10 & 0.91 & 5.0 & 0.91 & 0 \\
\hline B & Harrowed clay & 10 & 0.86 & 5.5 & 0.88 & 2 \\
\hline $\mathrm{C}$ & Harrowed clay & 10 & 0.85 & 4.5 & 0.90 & 6 \\
\hline A & Asphalt & 30 & 0.85 & 5.0 & 0.91 & 7 \\
\hline B & Asphalt & 30 & 0.46 & 4.0 & 0.47 & 2 \\
\hline $\mathrm{C}$ & Asphalt & 41 & 0.49 & 3.0 & 0.50 & 2 \\
\hline A & Farm roadway & 10 & 0.69 & 4.5 & 0.71 & 3 \\
\hline B & Farm roadway & 14 & 0.57 & 4.5 & 0.55 & 3 \\
\hline $\mathrm{C}$ & Farm roadway & 14 & 0.59 & 4.5 & 0.62 & 5 \\
\hline
\end{tabular}

trailer caused these low acceleration values over asphalt and farm roadway. Instead, on the ISO track, the distance of the wooden slats and the difference in height between the two strip tracks caused high horizontal acceleration also at low forward speeds.

RMS acceleration values on field and on ISO track along the y direction (Table 4) are among those more similar than the RMS measured pairs along the $\mathrm{x}$ axis: absolute variation rates are lower, also if tractor C presents a $185 \%$ value between the asphalt and the ISO track RMS data. In this case, the tractor was running at $41 \mathrm{~km} / \mathrm{h}$ over the asphalt, and the low recorded acceleration value $\left(0.13 \mathrm{~m} / \mathrm{s}^{2}\right)$ is due to the flat, even surface which did not generate significant transversal movements.

Along the vertical direction (z axis, Table 5), tractor passages over the ISO track at a speed range between 3 and $5.5 \mathrm{~km} / \mathrm{h}$ gave out RMS values that were very similar to those measured over other surfaces: in fact, in the worst situation, there is a $10 \%$ difference.

\section{Frequency analysis}

We then analyzed the vibrational behavior of the tractor in terms of fundamental frequencies obtained in the test conditions presented above. The 1/3 octave band values for each surface, for each axis and for each forward speed (as in Tables 3, 4 and 5) are shown in Figure 1.

On the $\mathrm{x}$ axis, vibration energy was distributed between 2.5 and 3.15 $\mathrm{Hz}$ (for tractors B and C). For ISO-smooth track, unmetalled road and asphalt track, also $4 \mathrm{~Hz}$ was recorded for tractor A. On the y axis, the vibration energy was mainly distributed between 1.25 and $1.6 \mathrm{~Hz}$ for all tractors, whereas it was mostly found at $2.5 \mathrm{~Hz}$ for tractor $\mathrm{C}, 3.15 \mathrm{~Hz}$ for tractor $\mathrm{B}$, and $4 \mathrm{~Hz}$ for tractor $\mathrm{A}$ along the $\mathrm{z}$ axis. The tractor with the lowest mass (A, class I, $3430 \mathrm{~kg}$ ) recorded a vibration resonance of 4 $\mathrm{Hz}$, the class II tractor with a $4080 \mathrm{~kg}$ mass (B) showed a fundamental frequency between 2.5 and $3.15 \mathrm{~Hz}$, while tractor C (class II, $4380 \mathrm{~kg}$ ) mostly showed values of around $2.5 \mathrm{~Hz}$.

Tractor A recorded a resonance frequency of $4 \mathrm{~Hz}$ along the $\mathrm{x}$ and $\mathrm{z}$ axes on almost all surfaces. This frequency decreased to 3.15 and 2.5 $\mathrm{Hz}$ on a deformable surface such as harrowed clay or grass. In these conditions, the tire lugs go into the soil, do not return into the tire and do not bend the tire sidewalls. Along the $\mathrm{x}$ and $\mathrm{z}$ axes, the resonance frequency is usually higher when tractors run on the ISO-smooth track: this is due to the interaction of the tire lugs with the wooden slats. There is an inverse correlation tendency between mass and fundamental vibration frequency.

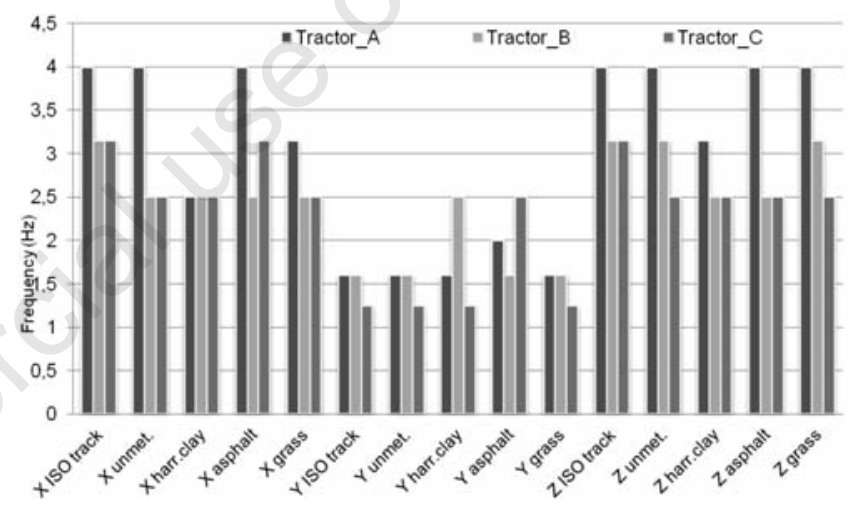

Figure 1. 1/3 octave band frequency values for each tractor (A, B and $\mathrm{C}$ ) in each test condition (ISO-smooth track, unmetalled road, harrowed clay, asphalt and grass), along the $\mathrm{x}, \mathrm{y}$ and $\mathrm{z}$ axes, at the speeds reported in Tables 3,4 and 5.

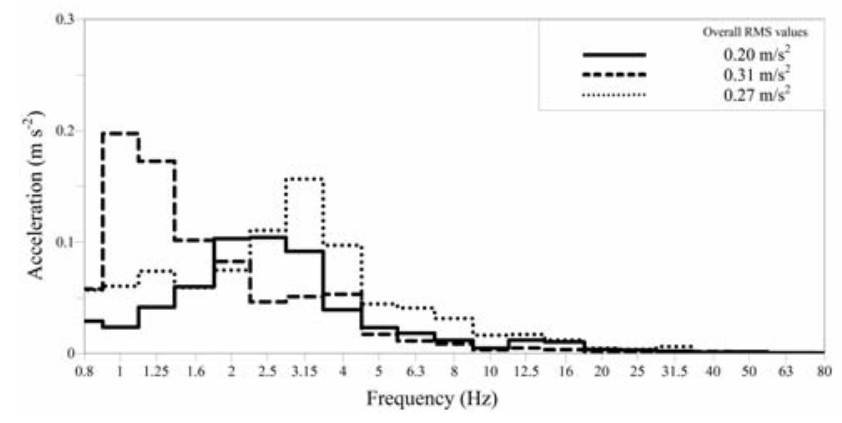

Figure 2. Overall root mean square (RMS) values and 1/3 frequency band of tractor $\mathrm{C}$ running on unmetalled farm roadway at $10 \mathrm{~km} / \mathrm{h}$ (continuous line) and on ISO track at $2 \mathrm{~km} / \mathrm{h}$ (dashed line) and at $6 \mathrm{~km} / \mathrm{h}$, (point line), $\mathrm{x}$ direction. 


\section{Frequency analysis and acceleration amplitude: two case studies}

We examined two case studies: tractors B and C crossing ISOsmooth track, harrowed clay (B) and unmetalled farm roadway (C) along $\mathrm{x}(\mathrm{C})$ and $\mathrm{z}(\mathrm{B})$ axes. As a rule, along the y axis, only when all the tractors were run at $30 \mathrm{~km} / \mathrm{h}$ (or over) on the asphalt track was there no intersection with the acceleration measured on the ISO-smooth track, always as a consequence of the fact that the crossed surfaces were flat and even, thus there was no visible transversal movement of the tractor. For this reason, it was not considered to be of interest to present a case study along the y axis.

Figure 2 shows three curves describing acceleration patterns, 1/3 octave band and $\mathrm{x}$ axis of tractor $\mathrm{C}$ running on unmetalled farm roadway at $10 \mathrm{~km} / \mathrm{h}$ (continuous line), and on the ISO-smooth track at 2 $\mathrm{km} / \mathrm{h}$ (dashed line) and $6 \mathrm{~km} / \mathrm{h}$ (dotted line). At $2 \mathrm{~km} / \mathrm{h}$, on the ISOsmooth track the tractor has the highest longitudinal acceleration at 1 $\mathrm{Hz}, 0.31 \mathrm{~m} / \mathrm{s}^{2} \mathrm{RMS}$; at $6 \mathrm{~km} / \mathrm{h}$, the RMS value decreased to $0.27 \mathrm{~m} / \mathrm{s}^{2}$ and the energy presented a peak at $3.15 \mathrm{~Hz}$. A further analysis of other shapes for the same tractor running at a higher velocity on the ISOsmooth track showed there was no change in this latter frequency distribution: only the RMS increased. On the ISO track, the longitudinal acceleration $\mathrm{x}$ shifted in frequency (from 1 to $3.15 \mathrm{~Hz}$ ) with the increase of machine forward speed: this also occured for the other tractors (with different frequency ranges) and may have been caused by the tire radial damping and stiffness variation in function of their angular velocity on the smoother ISO track.

The rise in forward speed may produce an increase in the inertia of the vehicle and, as a consequence, the machine is less prone to the rolling caused by the smoother ISO track geometry. In this case study, the same considerations are not possible for the tractor running on the unmetalled farm roadway because over this surface the forward speed was a constant $10 \mathrm{~km} / \mathrm{h}$. Considering the $\mathrm{z}$ axis, an interesting result is obtained crossing the ISO track at $5.5 \mathrm{~km} / \mathrm{h}$ : the energy distribution transmitted to the cab floor of tractor B is similar to the one obtained from the harrowed soil tractor passages at $10 \mathrm{~km} / \mathrm{h}$ (Figure 3 ). Values for $1 / 3$ octave band acceleration were very similar for the two surfaces at the vertical direction $\mathrm{z}$, differing by only $2.3 \%$ (RMS $0.86 \mathrm{~m} / \mathrm{s}^{2}$ for harrowed clay and $0.88 \mathrm{~m} / \mathrm{s}^{2}$ for ISO track). On the harrowed clay, the vibration energy was mainly gathered around $2.5 \mathrm{~Hz}$, while on the ISO track it shifted to $3.15 \mathrm{~Hz}$. This happened for all the tractors examined, regardless of the mass and tire type, and it was probably caused by the energy required to deform the soil surface rather than by the energy dissipated in the tires (Lines, 1991a; Lines, 1991b; Lines, 1992).

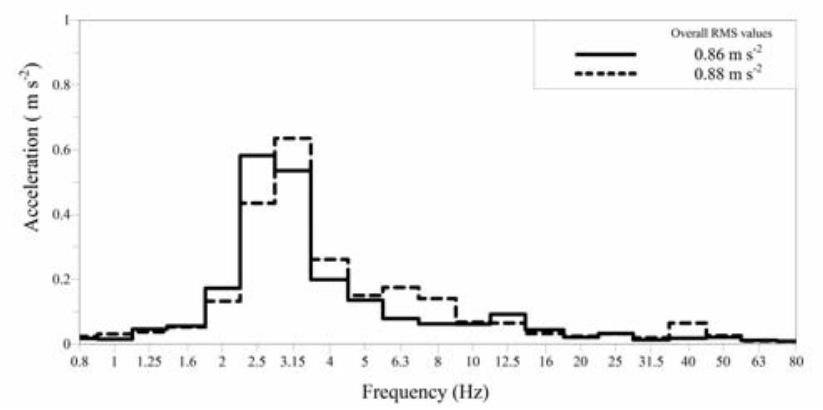

Figure 3. Overall root mean square (RMS) values and 1/3 frequency band of tractor $B$ crossing harrowed clay $(10 \mathrm{~km} / \mathrm{h}$, continuous line) and ISO track ( $5.5 \mathrm{~km} / \mathrm{h}$, dashed line), $\mathrm{z}$ axis.

\section{Conclusions}

This study did not aim to measure and compare vibration levels among tractors running on different surfaces but rather to start to study the vibrational behavior of different tractors running on different surfaces and then on the ISO-smooth track.

There are obvious difficulties in trying to define a simplified study approach to a problem as complex as this. Nonetheless, the results obtained in this first comparison of three different tractors running on several agricultural surfaces and on an ISO-smooth track are encouraging. For example, to confirm vibration values of a tractor crossing a grass surface, a manufacturer should simply run the tractor on an ISOsmooth track at a forward speed of $4.5 \mathrm{~km} / \mathrm{h}$ to obtain reliable data, especially along the $\mathrm{z}$ axis (Table 5).

In the $\mathrm{z}$ direction, the average RMS accelerations recorded were not only similar in all the conditions examined, but even the differences observed when the $1 / 3$ frequency bands were superimposed were negligible, also considering the reaction of the tires over surfaces of different degrees of roughness (Deboli, 2008).

This study demonstrates that the smoother ISO track may simulate some common vibratory conditions, such as those found when the tractor is run without a trailer across grass or unmetalled farm roadway. Further tests are required to evaluate agricultural operations with tractors coupled to other farm machinery. For tractor movement on asphalt, with or without a trailer, different types of artificial tracks should be used and these will be the subject of future studies.

\section{References}

Banfo GL, Deboli R, Miccoli G, 1997. Vibration active control device application to earth-moving machines seats. Proc. 7th European ISTVS, Ferrara, Italy, pp 462-469.

Bovenzi M, 1994. Low-back disorders in agricultural tractor drivers exposed to whole-body vibration and postural stress. Appl. Ergon. 25:231-41.

Deboli R, Calvo A, Preti C, Paletto G, 2008. Whole body vibration (WBV) transmitted to the operator by tractors equipped with radial tires. Proc. Int. Conf. Innovation Technology to Empower Safety, Health and Welfare in Agriculture and Agro-food Systems, Ragusa, Italy.

Deprez K, Moshou D, Ramon H, 2005a. Comfort improvement of a nonlinear suspension using global optimization and in situ measurements. J. Sound Vib. 284:1003-14.

Deprez K, Moshou D, Anthonis J, Baerdemaeker JD, Ramon H, 2005b. Improvement of vibrational comfort by passive and semi-active cabin suspensions. Comput. Electron. Agric. 49:431-40.

European Commission (EEC), 1978. Commission Decision of 25 July 1978 concerning the approximation of the laws of the Member States relating to the driver's seat on wheeled agricultural or forestry tractors, 78/764/EC. In: Official Journal, L 255, 18/09/1978, p 1.

European Commitee for Standardization (CEN), 2003. Commission Decision of 28 May 2003 concerning testing of mobile machinery in order to determine the vibration emission value. In: Official Journal, L 1032, 28/05/2003.

European Commitee for Standardization (CEN), 2006. Commission Decision approved on 18 April 2008 concerning mechanical vibration. Guideline for the assessment of exposure to whole-body vibration of ride on operated earth-moving machines using harmonized data measured by international institutes, organizations and manufacturers. ISO/TR 25398:2006 approved by CEN as a CEN/TS 15730:2008 without any modification.

ISO, 1997. Guide for the evaluation of human exposure to whole-body 
vibration. ISO 2631-1. Geneva, Switzerland. p 38.

ISO, 2001. Agricultural wheeled tractors and field machinery. Measurement of whole-body vibration of the operator. ISO 5008. Geneva, Switzerland. p 23.

Lines JA, Murphy K, 1991a. The radial damping of agricultural tractor tyres. J. Terramechanics 28:229-41.

Lines JA, Murphy K, 1991b. The stiffness of agricultural tractor tyres. J. Terramechanics, 28:49-64.

Lines JA, Peachey R0, Collins TS, 1992. Predicting the ride vibration of an unsuspended tractor using the dynamic characteristics of rolling tyres. J. Terramechanics 29:307-15.

Lines JA, Stiles M, Whyte RT, 1995. Whole body vibration during tractor driving. J. Low Freq. Noise V. 14:87-104.

Maytona AG, Kittusamyb NK, Ambrosea DH, Jobesa CC, Legault ML, 2008. Jarring/jolting exposure and musculoskeletal symptoms among farm equipment operators. Int. J. Ind. Ergon. 38:758-66.

Paddan GS, Griffin MJ, 2002. Effect of Seating on Exposures to WholeBody Vibration in Vehicles. J. Sound Vib. 253:215-41.

Scarlett AJ, Price JS, Semple DA, Stayner RM, 2005. Whole-body vibration on agricultural vehicles: evaluation of emission and estimated exposure levels. HSE Research Report No. 321.

Scarlett AJ, Price JS, Stayner RM, 2007. Whole-body vibration: Evaluation of emission and exposure levels arising from agricultural tractors. J. Terramechanics 44:65-73. 